\title{
Work in Progress: Reviving a Transport Phenomena Course by Incorporat- ing Simulation and Laboratory Experiences
}

\author{
Dr. Marcia Pool, University of Illinois, Urbana-Champaign
}

Dr. Marcia Pool is a Lecturer in bioengineering at the University of Illinois at Urbana-Champaign. In her career, Marcia has been active in improving undergraduate education through developing problem-based laboratories to enhance experimental design skills; developing a preliminary design course focused on problem identification and market space (based on an industry partner's protocol); and mentoring and guiding student teams through the senior design capstone course and a translational course following senior design. To promote biomedical/bioengineering, Marcia works with Women in Engineering to offer outreach activities and is engaged at the national level as Executive Director of the biomedical engineering honor society, Alpha Eta Mu Beta.

Prof. Rohit Bhargava, University of Illinois, Urbana-Champaign

Rohit Bhargava is Bliss Faculty Scholar of Engineering and Professor at the University of Illinois at Urbana-Champaign. He is a faculty member with affiliations in several departments across campus (Primary - Bioengineering: Affiliated - Electrical and Computer Engineering, Mechanical Science and Engineering, Chemical and Biomolecular Engineering and Chemistry) as well as the Beckman Institute for Advanced Science and Technology. Rohit received dual B.Tech. degrees (in Chemical Engineering and Polymer Science and Engineering) from the Indian Institute of Technology, New Delhi in 1996 and his doctoral thesis work at Case Western Reserve University (Department of Macromolecular Science and Engineering) was in the area of polymer spectroscopy. He then worked as a Research Fellow at the National Institutes of Health (2000-2005) in the area of biomedical vibrational spectroscopy. Rohit has been at Illinois since as Assistant Professor (2005-2011), Associate Professor (2011-2012) and Professor (2012-). Rohit was the first assistant professor hired into the new Bioengineering department and played a key role in the development of its curriculum and activities. He later founded and serves as the coordinator of the Cancer Community @ Illinois, a group dedicated to advancing cancer-related research and scholarship on campus. Research in the Bhargava laboratories focuses on fundamental theory and simulation for vibrational spectroscopic imaging, developing new instrumentation and developing chemical imaging for molecular pathology. Using 3D printing and engineered tumor models, recent research seeks to elucidate hetero-cellular interactions in cancer progression. Rohit's work has been recognized with several research awards nationally. Among recent honors are the Meggers Award (Society for applied spectroscopy, 2014), Craver Award (Coblentz Society, 2013) and the FACSS Innovation Award (2012). Rohit has also been recognized for his dedication to teaching in the College of Engineering (Rose and Everitt awards) and he is routinely nominated to the list of teachers ranked excellent at Illinois.

\section{Prof. Paul A. Jensen, University of Illinois, Urbana-Champaign}

Paul Jensen is a Research Assistant Professor at the University of Illinois at Urbana-Champaign in the Department of Bioengineering and the Carl R. Woese Institute for Genomic Biology. He received bachelor degrees in chemical and biomedical engineering at the University of Minnesota and a Ph.D. in biomedical engineering from the University of Virginia. Paul completed postdoctoral training at Boston College before joining the University of Illinois in 2016.

\section{Dr. Karin Jensen, University of Illinois, Urbana-Champaign}

Karin Jensen is a Lecturer in bioengineering at the University of Illinois at Urbana-Champaign. At UIUC she teaches undergraduate courses and serves as an academic advisor. Before joining UIUC she completed a post-doctoral fellowship at Sanofi Oncology in Cambridge, MA. She earned a bachelor's degree in biological engineering from Cornell University and a Ph.D. in biomedical engineering from the University of Virginia. 


\section{Work in Progress: Reviving a Transport Phenomena Course by Incorporating Simulation and Laboratory Experiences}

\section{Introduction}

While biomedical engineering/bioengineering curriculums vary, sometimes greatly, between institutions, transport phenomena is required in over $70 \%$ of ABET accredited programs ${ }^{1}$. The application of transport phenomena (momentum, heat, and mass) is extensive in the biomedical field, and understanding the interactions between phenomena allows for enhanced design and optimization of devices and sensors. For instance, Roche Diagnostics utilized COMSOL, a multiphysics software package, to optimize their glucometer test strip design; two simulations were performed: (1) a simulation combining enzyme and electrode kinetics to predict the sensor response to different direct current profiles and (2) a simulation to predict the electrode sensitivity to hematocrit in the blood sample ${ }^{2}$. Medtronic engineers used COMSOL to optimize a thermal ablation probe design to achieve more precise tissue ablation zones; simulations were developed to analyze heat transfer in tissue as water in tissue vaporized which affects the precision of microwave ablation - the goal is real time feedback to enhance ablation precision ${ }^{3}$. It is well understood that modeling is a powerful technique for engineers to determine the best parameters to use in a design, and in many fields, even at the undergraduate level, modeling has greatly advanced with the use of simulation software.

However, many biomedical transport courses continue to be taught in a traditional, lecture-based format without the use of simulation. Since much of the class materials are derived from profound advances in early-mid decades of the $20^{\text {th }}$ century as well as availability of comprehensive textbooks (Bird, Stewart, and Lightfoot; Truskey; Fournier), instructors have often continued to cover "classical" problems and methods in teaching transport phenomena. The teaching format usually consists of thorough analytical analysis and application of mathematics to gain insight into physical phenomena. This format struggles to engage students and does not reflect the reliance of modern computer simulation on specific, real-world biomedical transport problems. As educators, we sought to re-evaluate our traditional teaching of transport to reflect what students will encounter in their careers, instill the use of modeling as a precursor to design, and promote a deeper understanding of transport concepts by allowing students to model, visualize, and solve more complex biomedical problems.

While simulations are effective in promoting an understanding of the effects of parameters in a particular model, hands-on preparation and testing of the simulation models moves students further in the design cycle. An even further progression would be to allow students to compare experimental results with simulation in the context of underlying analytical models. For instance, simulations, including Finite Element Modeling (FEM) and Simulation Program with IC Emphasis (SPICE), have been used in laboratories to allow students to predict results of handson experiments as well as extend the experience beyond the limitations of hands-on experiment ${ }^{4}$. We envision a change in the philosophy of teaching transport phenomena-as opposed to a skill set gained for application to complex problems - we propose to model and visualize complex 
multi-phenomena problems as a teaching tool. This approach will not only provide students a sense of magnitude and "feel" for the phenomena (similar to flight simulations introducing various situations to pilots ${ }^{4}$ ) but will also encourage exploration of large parameter spaces to augment their experience. Further, we view the course as a critical bridge from early departmental courses to senior design. Comparisons between experiment and simulation will increase student understanding of simulation to guide the design process but also introduce the limitations of simulations. In addition, students will gain more experience in designing experiments, using laboratory equipment, and analyzing and interpreting data.

\section{Course structure}

To better engage our students and further develop their engineering design skills, we redesigned a lecture-based biomedical transport course (3-fifty minute lectures per week) into a problembased learning course that combines lecture, simulation, and experimental components (Table 1). COMSOL was chosen as the simulation software due to its (1) use in industrial design and optimization, (2) use in several chemical engineering transport courses ${ }^{5,6}$, and (3) familiarity to the instructors.

Table 1. Conceptual content and modeling applications in redesigned transport course.

\begin{tabular}{|c|c|c|}
\hline Phenomena & Conceptual Topics & Simulation (or *Experiment) \\
\hline Momentum & $\begin{array}{ll}\text { - } & \text { Fluid flow (cardiovascular) } \\
\text { - } & \text { Rheology } \\
\text { - } & \text { Navier-Stokes equation } \\
\text { - } & \text { Bernoulli's equation, } \\
& \text { Reynold's number, } \\
& \text { dimensional analysis } \\
\end{array}$ & $\begin{array}{l}\text { - Pipe flow } \\
\text { - Newtonian/non-Newtonian } \\
\text { concentric cylinder rheometer } \\
\text { - Viscous and inertial flow } \\
\text { - Visual stream functions }\end{array}$ \\
\hline Mass & $\begin{array}{ll}\text { - } & \text { Stokes-Einstein diffusion } \\
\text { - } & \text { Fick's law, time varying } \\
\text { - } & \text { Diffusion-limited reactions } \\
\text { - } & \text { Convection-diffusion equation }\end{array}$ & $\begin{array}{ll}\text { - } & \text { Controlled release: Semi-infinite } \\
\text { diffusion } \\
\text { - } \\
\text { - Diffusion in series (e.g. drug patch) } \\
* \quad \text { Co- and counter-current flow }\end{array}$ \\
\hline Microfluidics & $\begin{array}{l}\text { - Convection-diffusion equation } \\
\text { in flow channels } \\
\text { - Measuring rate constants }\end{array}$ & $\begin{array}{ll}\text { Steady/unsteady flow transitions } \\
\text { (droplet formation) }\end{array}$ \\
\hline Heat & $\begin{array}{l}\text { - Thermal transport in fin } \\
\text { - } \quad \text { Thermal convective transport }\end{array}$ & - Thermal ablation of tumor \\
\hline
\end{tabular}

For the pilot offering in spring 2016, fifty, junior-level bioengineering students enrolled and divided into teams of two to three students. The course was structured to, in a typical week, deliver one "theory" lecture, one "analytical problems" lecture, and one simulation lecture. Lectures (1) provided foundational knowledge and motivated the use of transport principles to solve biomedical problems, (2) explained the problem formulation and software implementation, and (3) discussed how transport processes are modeled and tested in a laboratory experiment. Students were trained on the simulation software before completing three modules (momentum, mass, heat) each with a simulation component. The culmination of the course was an end of the 
semester project in which each team (1) identified and explained the governing concepts of a system, (2) designed a simulation to model the system, and (3) explained the limitations of the simulation. One major challenge was students being unfamiliar with the software yet required to quickly develop understanding and ability to implement the simulation software. While students were unfamiliar with the software, the proposed experiments build on laboratory skills developed in earlier coursework (Table 2). Mindful of the first offering, we did not include laboratory experiences in spring 2016. Evaluation of challenges and timelines indicate incorporating two new situations (simulation and laboratory exercises) into a three credit hour lecture may not be feasible; in the future, the laboratory exercises may be best suited for a laboratory course or as end of semester projects. Through the redesigned structure, we introduce students to new material, train students on new software, and propose to increase student understanding and application of previously-learned laboratory techniques to further develop engineering team and design skills.

Table 2. Hands-on experiments to connect simulation and practice

\begin{tabular}{|l|l|}
\hline Phenomena & Experiment \\
\hline $\begin{array}{l}\text { Coupled } \\
\text { (mass and momentum) }\end{array}$ & $\begin{array}{l}\text { Co-current and counter current flow } \\
\text { - Class: Design dialysis cartridge for optimal mass exchange. } \\
\text { Lab: Measure experimental parameters by fitting data to } \\
\text { models. }\end{array}$ \\
\hline $\begin{array}{l}\text { Microfluidics } \\
\text { (transition } \\
\text { region of steady to } \\
\text { unsteady flow) }\end{array}$ & $\begin{array}{l}\text { Creating picoliter droplets } \\
\text { - Class: COMSOL simulation to predict required flow rates } \\
\text { - Lab: Test flow rates identified through simulation }\end{array}$ \\
\hline
\end{tabular}

\section{Assessment}

To evaluate the course structure as well as gains in student knowledge and ability, we employed a combination of qualitative and quantitative techniques. Surveys (Likert and free response) were administered to determine student understanding of the importance of simulation/modeling in design and optimization, and a post-course focus group was conducted to identify strengths and areas of improvement in course delivery. Simulation work (team) and exams (individual) were employed to evaluate student understanding of conceptual material and application of software for modeling. In the future, laboratory exercises (team) and documentation (team) will allow for evaluation of students' ability to connect conceptual material and simulation to practice. A miniproject during the semester allowed the students to hone their skills and develop confidence. Finally, the project (team) was utilized to evaluate students' ability to design a model to investigate a real-world situation.

\section{References}

[1] D. W. Gatchell and R. A. Linsenmeier. "Similarities and Differences in Undergraduate Biomedical Engineering Curricula in the United States," in American Society of Engineering Education Annual Conference, Indianapolis, IN 2014. 
[2] L. Carver. "Bringing Glucose Monitoring to New Levels through Integrated Sensor Design," IEEE Spectrum: Multiphysics Simulation, September 2015, pp. 24-26.

[3] G. Dagastine. "Medtronic Advances Ablation Technology with Multiphysics Simulation," IEEE Spectrum: Multiphysics Simulation, September 2015, pp. 11-13.

[4] L. D. Feisel and A. J. Rosa. "The Role of the Laboratory in Undergraduate Engineering Education," Journal of Engineering Education, vol. 94 issue 1, pp. 121-130, 2005.

[5] W. Clark and D. DiBiasio. "Computer Simulation of Laboratory Experiments for Enhanced Learning," in American Society of Engineering Education Annual Conference, 2007.

[6] J. Keith, F. Morrison, and J. King. "Finite Element Modules for Enhancing Undergraduate Transport Courses: Applications To Fuel Cell Fundamentals," in American Society of Engineering Education Annual Conference, 2007. 